\title{
MEWUJUDKAN PEREMPUAN TANGGUH BENCANA MELALUI PENINGKATAN KESIAPSIAGAAN BENCANA GEMPABUMI DI PIMPINAN CABANG NASYIATUL AISYIYAH KLATEN SELATAN
}

\author{
Ratih Puspita Dewi, Wiwin Handitcianawati, dan Roby Hermawan \\ Pendidikan Geografi, Universitas Muhammadiyah Surakarta \\ Email: rpd229@ums.ac.id
}

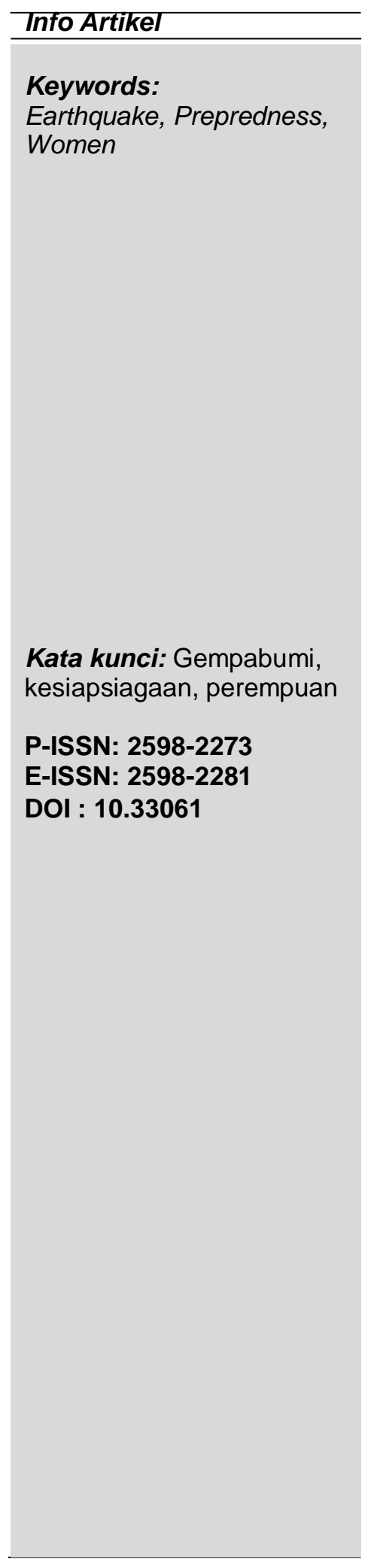

\begin{abstract}
Earthquake is a natural phenomena that occurs in the earth's surface in the form of shaking or vibrating of the surface of the earth because of the sudden movement of lithosphere cause of tectonic plates. The International Federation of Red Cross and Red Crecent Societies (2010) state that women and children are generally the main victims of natural disasters, this is due to higher casualities among women and girls, it is because of cultural constraints in the form of women's mobility, the lack of skills that women have compared to men, and women's physical strength is smaller compared to men. The aims was to minimized women as the earthquake disaster victim by improving knowledge, awareness, and preparedness of earthquake. The method was by giving socialization about earthquake in South Klaten Nasyiatul Aisyiyah Branch Leader. The targeted output was (1) increasing women's awareness of the importance of understanding earthquake mitigation both before, emergency response, and postdisaster, (2) growing awareness that earthquake occurs at anytime so that women must prepared for disaster anywhere and anytime, (3) improving women's preparedness of earthquake in order to reduce the risk of women as earthquake disaster's victims
\end{abstract}

\section{Abstrak}

Gempabumi (earthquake) merupakan suatu fenomena alami yang terjadi pada kulit bumi berupa bergoncangnya atau bergetarnya bumi karena adanya pergerakan pada lapisan batuan secara tiba-tiba disebabkan karena lempeng tektonik. International Federation of Red Cross and Red Crescent Societies (2010) menyebutkan bahwa perempuan dan anak pada umumnya merupakan korban utama dalam bencana alam, hal ini dikarenakan korban yang tewas lebih tinggi pada perempuan dan anak perempuan, penyebabnya karena kendala budaya berupa mobilitas perempuan, kurangnya ketrampilan yang dimiliki perempuan dibandingkan dengan laki-laki, serta kekuatan fisik perempuan yang lebih kecil dibandingkan dengan laki-laki. Tujuan dari kegiatan ini adalah untuk meminimalkan resiko jatuhnya korban perempuan dalam bencana gempabumi dengan upaya meningkatkan kesadaran, kewaspadaan, dan kesiapsiagaan terhadap bencana gempabumi. Metode pelaksanaannya dengan melakukan sosialisasi kesiapsiagaan bencana gempabumi di Pimpinan Cabang Nasyiatul Aisyiyah Klaten Selatan. Target luaran dari kegiatan ini adalah (1) menumbuhkan kesadaran kepada kaum perempuan terhadap pentingnya pemahaman mitigasi bencana gempabumi baik sebelum, saat tanggap darurat maupun pasca bencana, (2) menumbuhkan kewaspadaan bahwa bencana gempabumi dapat terjadi sewaktu-waktu sehingga kaum perempuan harus siap me $\mathrm{n} \mathrm{g} \mathrm{h}$ a d a $\mathrm{p}$ i bencana kapan saja dan dimana saja, dan (3) meningkatkan kesiapsiagaan kaum perempuan terhadap bencana gempabumi sehingga mengurangi resiko terjadinya korban bencana dari pihak perempuan. 


\section{PENDAHULUAN}

Gempa bumi (earthquake) adalah suatu fenomena bergetar atau bergoncangnya bumi karena adanya pergerakan/pergeseran lapisan batuan yang terdapat pada kulit bumi secara tibatiba akibat lempeng-lempeng tektonik (Sunarjo dkk, 2012). Lebih lanjut Sunarjo dkk, (2012) menyatakan bahwa gempa bumi dapat terjadi kapan saja dan dimana saja namun demikian, konsentrasi gempabumi cenderung terjadi pada tempat-tempat tertentu saja dilapisan kulit bumi. Gempa bumi tidak terjadi disembarang tempat dimuka bumi, akan tetapi pada umumnya gempabumi terjadi disekitar batas lempeng bumi, yang membentuk jalur gempabumi dunia dan terjadi disekitar sesar. Menurut Dowrick, D.J. (2003) Akibat atau dampak utama yang menjadi perhatian dalam kejadian gempa bumi adalah jatuhnya korban manusia, berupa kematian dan cedera.

Menurut Chang, et al,(2018) selama kejadian bencana gempabumi, kurangnya kesiapsiagaan baik dari pemerintah maupun dari masyarakat dapat mengakibatkan luka serius dan korban jiwa. Hal ini sejalan dengan pendapat Kusky (2008) bahwa pengetahuan tentang bencana alam dapat menuntun seseorang untuk menjalani kehidupan yang lebih aman, memberikan panduan tentang dimana membangun rumah, tempat bepergian, dan apa yang dilakukan selama keadaan darurat bencana alam. Seiring dengan besarnya intensitas terjadinya bencana alam khususnya gempabumi maka pengetahuan dan kesiapan terhadap bencana tersebut merupakan salah satu hal yang esensial terutama bagi mereka yang hidup di daerahdaerah yang rawan bencana.

Bencana gempabumi dapat menyerang siapa saja baik laki-laki dan perempuan dewasa maupun anak-anak. Dalam aspek kebencanaan masalah gender merupakan salah satu aspek yang esensial. Hal ini dikarenakan adanya perbedaan kapasitas dan aktivitas diantara laki-laki dan perempuan dalam menghadapi bencana. UNDP (2010) menyebutkan bahwa gender merupakan variabel penting karena telah jelas bahwa mereka yang hidup dalam kemiskinan lebih rentan terhadap dampak bencana dan mayoritas orang miskin di dunia (70\%) adalah wanita. Telah sering diamati pula bahwa karena kerentanan yang lebih tinggi dan adanya marjinalisasi terhadap kaum perempuan, perempuan lebih terpengaruh oleh bencana yang lebih besar atau lebih kecil daripada laki-laki, meskipun tidak ada data statistik yang tersedia. Lebih lanjut UNDP (2010) menyebutkan bahwa wanita, pria, anak laki-laki dan perempuan, seringkali memiliki kebutuhan yang berbeda sebelum, selama, dan setelah bencana, keadilan gender dapat berwujud perbedaan target sumberdaya dalam upaya pemulihan dan untuk memfasilitasi partisipasi penuh perempuan dalam kesiapsiagaan dan sosialisasi mitigasi bencana. 
Perempuan dan anak perempuan umumnya cenderung menjadi korban utama dalam bencana alam. Hal ini karena korban yang tewas lebih tinggi diantara perempuan dan anak perempuan termasuk didalamnya (1) kendala budaya berupa sulitnya mobilisasi perempuan yang dapat menghambat penyelamatan diri (2) kurangnya ketrampilan misalnya berenang dan memanjat pohon, yang hal ini secara tradisional diajarkan kepada laki-laki (3) kekuatan fisik lebih kecil dibandingkan dengan laki-laki (International Federation of Red Cross and Red Crescent Societies, 2010).

Memahami bagaimana hubungan gender membentuk kehidupan wanita dan pria merupakan hal yang sangat penting dalam pengurangan resiko bencana. Ini karena perbedaan peran, tanggung jawab, dan akses sumberdaya antara pria dan wanita mempengaruhi bagaimana mereka akan terdampak oleh berbagai bencana dan bagimana mereka pulih dari bencana. Ketidaksetaraan kekuatan antara wanita dan laki-laki berarti bahwa, terlepas dari ketahanan yang luar biasa dan kapasitas untuk bertahan hidup yang sering ditunjukkan oleh perempuan dalam menghadapi bencana, mereka juga mengalami kerentanan khusus gender (Ciampi, et al. 2011). Oleh karena itu, dalam upaya mitigasi bencana gempabumi perlu melibatkan perempuan agar mereka tidak menjadi mayoritas korban dalam kejadian bencana. Salah satu upaya yang dapat dilakukan adalah dengan meningkatkan pengetahuan dan kesiapsiagaan perempuan dalam menghadapi bencana gempabumi.

\section{RUMUSAN MASALAH}

Gempabumi yang terjadi di Yogyakarta menimbulkan kerusakan tidak hanya di Daerah Istimewa Yogyakarta melainkan juga wilayah Jawa Tengah meliputi sebagian wilayah Klaten dan Boyolali. Di Jawa Tengah terdapat korban meninggal dunia dan lainnya luka-luka serta banyaknya rumah rusak. Lebih spesifik di Kabupaten Klaten merupakan salah satu kabupaten di Jawa Tengah yang terkena dampak gempabumi, terdapat korban meninggal, luka berat dan rumah roboh akibat gempa bumi. Menurut Sunarjo, dkk, (2012) korban tewas pada bencana pada umumnya karena tertimpa bangunan yang roboh, sementara korban luka-luka juga banyak terjadi karena kepanikan yang luar biasa. Kepanikan yang muncul salah satunya bisa disebabkan karena kurangnya pengetahuan dan kesiapsiagaan masyarakat dalam menghadapi bencana gempabumi. Berkaca dari kejadian tersebut maka kesadaran dan kesiapsiagaan terhadap bencana gempabumi harus ditingkatkan mengingat bencana gempabumi dapat terjadi setiap saat dan sulit untuk diprediksi. Klaten Selatan merupakan salah satu wilayah di Kabupaten Klaten yang berpotensi terjadi gempabumi karena lokasinya 
yang dekat dengan jalur gempabumi di Indonesia. Laki-laki dan perempuan baik dewasa maupun anak-anak semua memiliki potensi menjadi korban bencana gempabumi namun, mengingat bahwa perempuan memiliki tingkat kerentanan yang lebih tinggi untuk menjadi korban dalam bencana dibandingkan dengan laki- laki maka upaya mitigasi bencana terhadap kaum perempuan merupakan hal yang sangat penting untuk dilakukan.

\section{METODE PENELITIAN}

Peserta kegiatan ini adalah anggota Pimpinan Cabang Nasyiatul Aisyiyah Klaten Selatan. Metode pelaksanaan berupa pemberian sosialisasi kesiapsiagaan terhadap bencana gempabumi kepada Pimpinan Cabang Nasyiatul Aisyiyah Klaten Selatan. Tahapan pelaksanaan meliputi: tahap sebelum pelaksanaan, pada tahap ini berupa analisis masalah dan situasi mitra serta pertimbangan solusi, selanjutnya pembekalan dan koordinasi bagi pihak- pihak yang terlibat dalam kegiatan ini yaitu dosen, mahasiswa dan pengurus serta anggota Pimpinan Cabang Nasyiatul Aisyiyah Klaten Selatan. Tahap selanjutnya merupakan tahap pelaksanaan pada tahap ini sosialisasi kesiapsiagan terhadap gempabumi meliputi penyampaian kegiatan yang perlu dilakukan sebelum bencana gempabumi, usaha pada saat tanggap darurat, kegiatan pasca bencana gempa bumi, dilanjutkan dengan diskusi dan tanya jawab dengan peserta kegiatan. Tahap terkahir berupa penyusunana laporan kegiatan.

\section{PEMBAHASAN}

Kegiatan pengabdian kepada masyarakat ini dilaksanakan pada hari Minggu, 11 November 2018 bertempat di SMP Muhammadiyah 1 Klaten dengan tema "Mewujudkan Masyarakat Tangguh Bencana Gempa Bumi di Pimpinan Cabang Nasyiatul Aisyiyah Klaten Selatan" dan diikuti oleh anggota Pimpinan Cabang Nasyiatul Aisyiyah Klaten Selatan selain itu hadir pula beberapa perwakilan KOKAM. Total peserta dalam kegiatan ini kurang lebih 64 orang. Peserta kegiatan ini berasal dari rentang usia yang cukup bervariasi mulai dari usia sekolah dan mahasiswa hingga para ibu rumah tangga yang memiliki beberapa anak. Kaitannya dengan kesiapsiagaan bencana ibu rumah tangga yang memiliki anak balita, manula, dan berkebutuhan khusus memiliki tanggung jawab yang berbeda nantinya dalam kesiapsiagaan bencana gempa bumi, sedangkan usia sekolah dan mahasiswa umumnya mengalami bencana gempa bumi pada usia dimana mereka memiliki informasi yang minim mengenai bencana gempa bumi. Pengabdian ini dimulai pada pukul 09.00 - 12.00 WIB yang bertempat di Aula SMP Muhammadiyah 1 Klaten. Bentuk kegiatan ini berupa sosialisasi 
kesiapsiagaan bencana gempa bumi bagi anggota Pimpinan Cabang Nasyiatul Aisyiyah Klaten Selatan.

Kegiatan pengabdian kepada masyarakat ini dibagi menjadi beberapa sesi dengan beberapa pembicara dosen Program Studi Pendidikan Geografi Universitas Muhammadiyah Surakarta. Pada sesi dengan materi kesiapsiagaan bencana gempa bumi disampaikan dengan menggunakan media powerpoint dengan menggunakan metode ceramah dan tanya jawab dengan peserta dengan peserta kegiatan. Materi yang disampaikan meliputi kegiatan apa saja yang dapat dilakukan sebelum, pada saat, dan sesudah bencana gempa bumi. Sebagian anggota Pimpinan cabang Nasyiatul Aisyiyah merupakan korban bencana gempa bumi yang berpusat di Bantul Daerah Istimewa Yogyakarta pada tahun 2006 yang meninggalkan bekas trauma kepada para korbannya mengingat kejadian bencana tersebut merupakan hal yang tidak diwaspadai terjadinya, hal ini dikarenakan di Kabupaten Klaten dalam jangka waktu yang lama tidak terjadi bencana gempa bumi sehingga pada saat terjadi gempa bumi pada tahun 2006 sebagian besar warga tidak siap menghadapi datangnya bencana tersebut, demikian pula dengan anggota Pimpinan Cabang Nasyiatul Aisyiyah, sebagian besar kesiapsiagaan bencana gempa bumi masih terbatas.

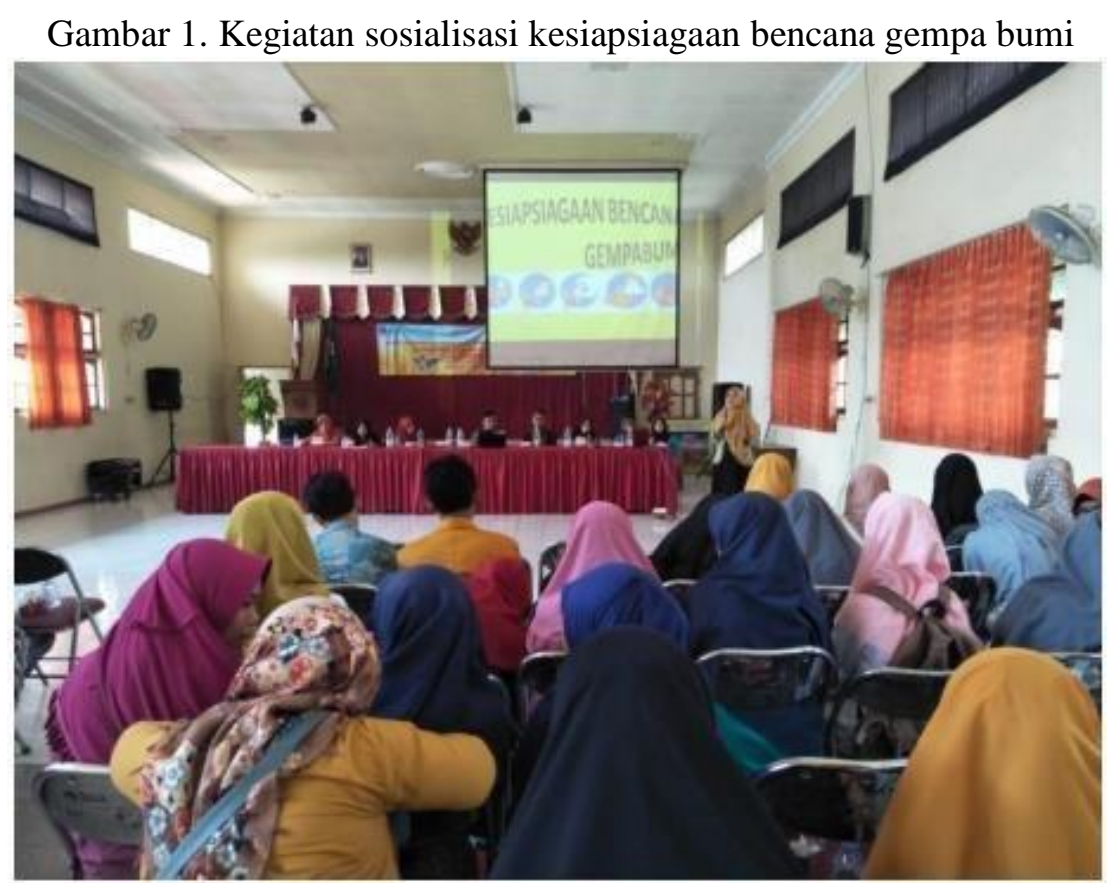

Sumber: Data Primer, 2018

Kegiatan pengabdian ini diawali dengan sambutan pembukaan dan doa dari panitia kegiatan yaitu Pimpinan Cabang Nasyiatul Aisyiyah Klaten Selatan yang dilanjutkan dengan penyampaian materi yang dibantu seorang moderator dari mahasiswa. Penyampaian materi kesipasiagaan bencana gempa bumi dilakukan dengan urutan penyampaian materi untuk kegiatan apa saja yang dapat dilakukan sebelum, pada saat (tanggap darurat) dan sesudah 
bencana gempa bumi. Termasuk didalalamnya adalah pentingnya memiliki rencana darurat keluarga dan pentingnya menyiapkan tas siaga bencana. Temuan dalam pengabdian ini adalah sebagian besar anggota Pimpinan Cabang Nasyiatul Aiyiyah Klaten Selatan memiliki kesiapsiagaan yang masih terbatas sehingga pada saat sesi diskusi dan tanya jawab pertanyaan yang disampaikan cukup bervariasi. Sebagai contoh terdapat peserta yang juga menjadi korban bencana gempa bumi berupa hancurnya rumah dan tidak mau menempati rumah tersebut dan memilih untuk membangun rumah ditempat yang lain. Hal ini menunjukkan masyarakat memiliki trauma terhadap kejadian bencana gempa bumi.

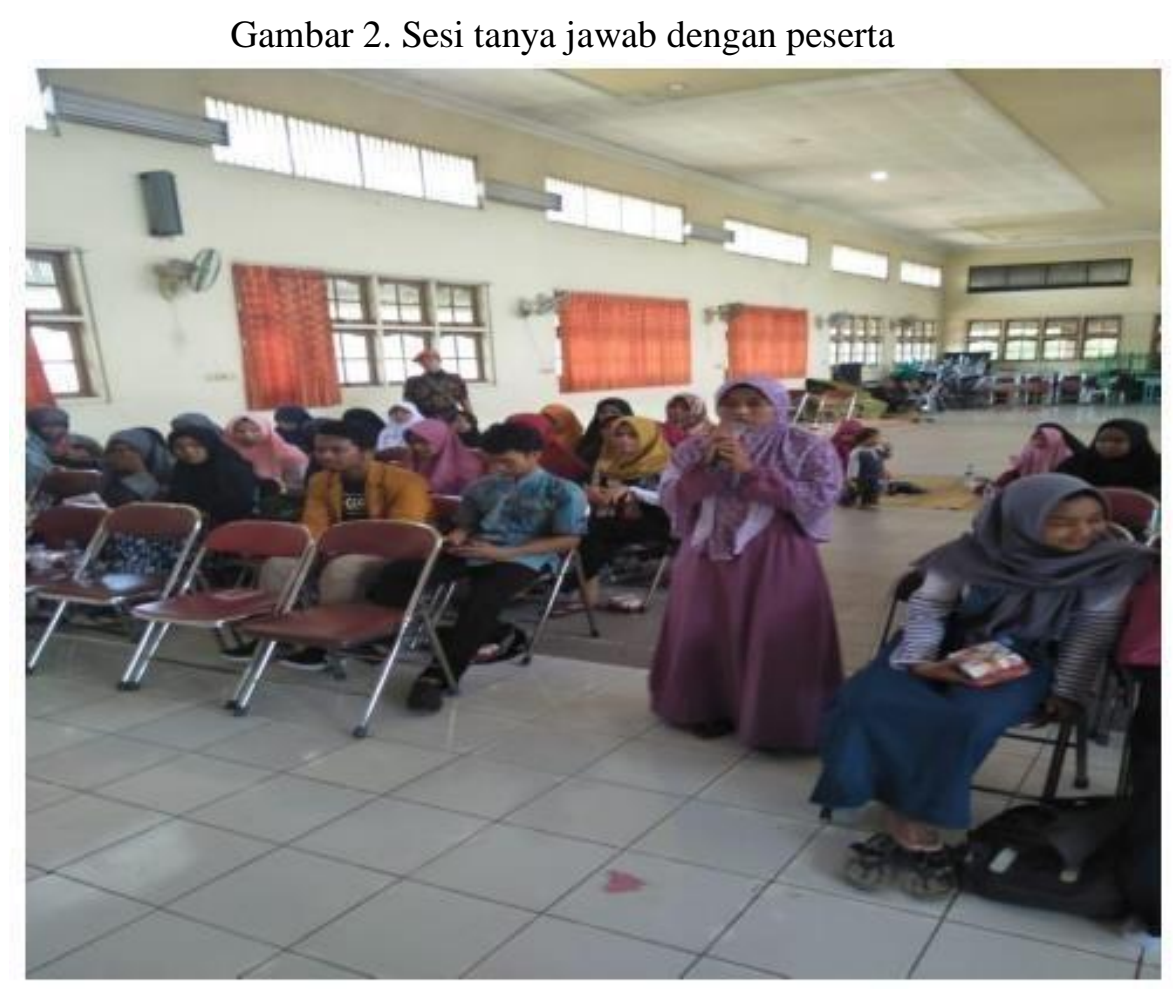

Sumber: Data Primer, 2018

Kaitannya dengan keberlanjutan dalam kegaiatan pengabdian kepada masyarakat ini, para anggota dapat berkonsultasi dengan narasumber maupun dengan saling bertukar pikiran dengan anggota Pimpinan Cabang Nasyiatul Aisyiyah lainnya melalui media sosial maupun melalui email. Peserta kegiatan pengabdian kepada masyarakat ini menginginkan dilaksanakan kembali kegiatan yang serupa berupa peningkatan kesadaran bencana gempa bumi di Klaten dengan cakupan wilayah yang lebih luas yaitu pada Pimpinan Daerah Nasyiatul Aisyiyah di Klaten mengingat kegiatan sosialisasi mengenai bencana di wilayah Kabupaten Klaten Khususnya pada Nasyiatul Aisyiyah masih minim disisi lain para anggotanya sangat membutuhkan informasi mengenai bencana agar memiliki kesiapan 
ketika bencana gempa bumi sewaktu-waktu terjadi di wilayah mereka. Diharapkan pada masa yang akan datang pengabdian masyarakat khususnya untuk peningkatan kesiapsiagaan terhadap bencana gempa bumi dapat dilanjutkan ditambah dengan kegiatan simulasi bencana gempa bumi bagi Pimpinan Daerah Nasyiatul Aisyiyah agar para pesertanya memiliki ketrampilan yang kontekstual dalam menghadapi bencana gempa bumi.

\section{CONCLUSION}

Kesiapsiagaan terhadap gempa bumi merupakan salah satu hal yang esensial untuk dimiliki oleh masyarakat khususnya pada kegiatan ini kesiapsiagaan terhadap bencana yang baik sudah seharusnya dimiliki oleh seluruh masyarakat baik yang berlokasi pada daerah rawan terhadap gempa bumi maupun yang tidak dikarenakan gempa bumi dapat terjadi kapan saja dan dimana saja dengan magnitud yang berbeda-beda. Lebih spesifik kepada kaum perempuan sudah seharusnya memiliki kesiapsiagaan terahadap bencana gempa bumi yang baik mengingat jumlah korban banyak dari pihak perempuan, selain itu pada kesehariannya perempuan memiliki sejumlah aspek yang membuatnya menjadi salah satu pihak yang rawan menjadi korban bencana gempa bumi dibandingkan dengan laki-laki, oleh karena itu peningkatan kesiapsiagaan terhadap bencana gempa bumi mutlak diperlukan oleh kaum perempuan. Kegiatan ini berusaha untuk meningkatkan kesadaran, kewasapadaan dan kesiapasaan kaum perempuan terhadap bencana gempa bumi sehingga kaum perempuan tahu apa yang harus dilakukan sebelum, pada saat dan pasca bencana gempa bumi. Salah satu langkah yang dapat dilakukan dengan memberikan sosialisasi peningkatan kesiapsiagaan terhadap gempa bumi. Nasyiatul Aisyiyah merupakan salah satu ortom Muhammadiyah yang bergerak dalam bidang pendidikan dan sosial, oleh karena itu peningkatan kesiapsiagaan terhadap bencana gempa bumi ini dapat dilakukan melalui Pimpinan Cabang Nasyiatul Aisyiyah yang dalam kegiatan ini adalah Pimpinan Cabang Nasyiatul Aisyiyah Klaten Selatan. Kegiatan ini merupakan salah satu upaya agar kaum perempuan khususnya pada Pimpinan Cabang Nasyiatul Aisyiyah Klaten Selatan meningkat kesadaran, kewaspadaan dan kesiapsiagaan terhadap bencana gempa bumi sehingga nantinya jika sewaktu-waktu terhadi bencana gempa bumi maka mereka siap untuk menghadapinya. 


\section{REFERENCES}

Chang, H.S. et, al. Comparing the Spatial Pattern of Earthquake Disaster Probability and Individual Risk Perception: A Case Study of Yongkang Township in Tainan, Taiwan. Journal Nat Hazard https://doi.org/10.1007/s11069-018-3369xCiampi, et al. 2011. Gender and Disaster Risk Reduction: A Training Pack. Oxford: Oxfam. Dowrick, D.J. 2003. Earthquake Risk Reduction. England: John Wiley \& Sons, Ltd.

International Federation of Red Cross and Red Crescent Societies. 2010. A Practical Guide to Gender-sensitive Approaches for Disaster Management. Switzerland: International Federation of Red Cross and Red Crescent Societies

Kusky, Timothy. 2008. Plate Tectonics and Earthquake Hazards. USA: Facts On File.

Sunarjo, dkk. 2012. Gempa Bumi Indonesia: Edisi Populer. Jakarta: Badan Meteorologi dan Geofisika.

UNDP. 2010. Gender in Disaster Risk Reduction (Information Brochure). Armenia: UNDP. 